\title{
Quantification of Pesticide Residues in Fresh Vegetables Available in Local Markets for Human Consumption and the Associated Health Risks
}

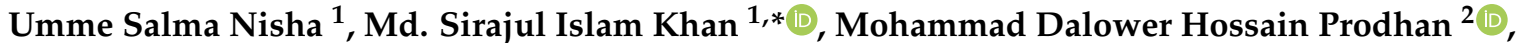 \\ Islam Md Meftaul 1,3,*(D), Noorjahan Begum ${ }^{1}$, Aney Parven ${ }^{1,3}$, Syfullah Shahriar ${ }^{3}$, Abdul Shukor Juraimi 4 \\ and Md. Abdul Hakim ${ }^{5}$
}

1 Department of Agricultural Chemistry, Sher-e-Bangla Agricultural University, Dhaka 1207, Bangladesh; ummenisha95@gmail.com (U.S.N.); nbegumsau@yahoo.com (N.B.); aney.parven@uon.edu.au (A.P.)

2 Pesticide Research \& Environmental Toxicology Section, Entomology Division, Bangladesh Agricultural Research Institute, Gazipur 1701, Bangladesh; mdhprodhan@gmail.com

3 Global Centre for Environmental Remediation (GCER), College of Engineering, Science and Environment, The University of Newcastle, Callaghan, NSW 2308, Australia; syfullah.shahriar@uon.edu.au

4 Faculty of Agriculture, Universiti Putra Malaysia, Serdang 43400, Malaysia; ashukor@upm.edu.my

5 Department of Agricultural Chemistry, Hajee Mohammad Danesh Science and Technology University, Dinajpur 5200, Bangladesh; ahakimhstu.upm@gmail.com

* Correspondence: sirajsau@sau.edu.bd (M.S.I.K.); mdmeftaul.islam@uon.edu.au (I.M.M.)

\section{check for} updates

Citation: Nisha, U.S.; Khan, M.S.I.; Prodhan, M.D.H.; Meftaul, I.M.; Begum, N.; Parven, A.; Shahriar, S.; Juraimi, A.S.; Hakim, M.A.

Quantification of Pesticide Residues in Fresh Vegetables Available in Local Markets for Human Consumption and the Associated Health Risks. Agronomy 2021, 11, 1804. https:// doi.org/10.3390/agronomy11091804

Academic Editor: Md Asaduzzaman

Received: 17 August 2021

Accepted: 6 September 2021

Published: 8 September 2021

Publisher's Note: MDPI stays neutral with regard to jurisdictional claims in published maps and institutional affiliations.

Copyright: (c) 2021 by the authors. Licensee MDPI, Basel, Switzerland. This article is an open access article distributed under the terms and conditions of the Creative Commons Attribution (CC BY) license (https:// creativecommons.org/licenses/by/ $4.0 /)$.

\begin{abstract}
Human health risks as a result of consuming pesticide residues in fresh vegetables have drawn serious attention to the scientific community, particularly in developing countries. This study analyzed country bean (Lablab purpureus L.) and eggplant (Solanum melongena L.) for widely used neonicotinoid, synthetic pyrethroid, and dithiocarbamate pesticide residues in order to ensure food safety. The analyzed vegetables contained residues of acetamiprid and cypermethrin in $17 \%$ of bean and $13 \%$ of eggplant samples, respectively; among them, $3 \%$ of bean and $1 \%$ of eggplant samples had residues of acetamiprid that were above the maximum residue limits set by the European Union (EU-MRLs). None of the samples for either of the analyzed vegetables contained the residue of thiram and lambda-cyhalothrin. In contrast, $83 \%$ of bean and $87 \%$ of eggplant samples had no detectable pesticides. Thus, the findings were surprising considering the repeated and overuse of pesticides in vegetables in the investigated areas. However, this outcome supports the general claim of pesticide adulteration in terms of the active ingredients, which is another drawback to ensuring food safety. The non-cancer health risk assessment based on the acute health risk to consumer (aHI) and chronic hazard quotient (HQ) indicates that contaminated vegetables might pose a potential threat to children's health and alarming for adults. This study reflects the overall scenario of pesticide residues in marketed vegetables of Barishal district of Bangladesh, which could help the consumers to bring awareness, and to take necessary actions by the pesticide suppliers and policymakers.
\end{abstract}

Keywords: country bean (Lablab purpureus L.); eggplant (Solanum melongena L.); pesticide adulteration; pesticide residues; health risk

\section{Introduction}

Vegetables are a crucial component of the human diet, which are often cultivated under high pressure in order to achieve higher yield [1]. The diverse climatic condition of Bangladesh confirms the availability of almost all varieties of vegetables for consumption throughout the year. Among them, country bean (Lablab purpureus L.) is a famous leguminous crop, covering approximately 11,000 hectares of land during the winter season after eggplant and tomato [2]. It is one of the income-generating crops because of its high yield and low production cost [2]. Globally, the crop is known by various names, e.g., hyacinth bean, bonavist bean, Dolichos bean, Indian bean, Egyptian bean, Lima bean, and 
faba bean [3]. It is very rich in carbohydrates, protein, fat, vitamins, and minerals [4] Moreover, its multifunctional use makes it more popular to consumers, e.g., pods cooked as vegetables and dry seeds are used in preparing various dishes [4]. Eggplant (Solanum melongena L.) is another vital solanaceous vegetable widely consumed and cultivated in Bangladesh and many countries of Asia and Africa. Approximately 50,000 hectares of land $(150,000$ farmers) is used to produce eggplant in Bangladesh [5]. Regarding the quantity of consumption, eggplant is ranked third after potato. It is a good source of fiber, copper, manganese, vitamin B6, and thiamine in tropical diets [6]. In addition, eggplant is a source of antioxidants, which helps to eliminate free radicals and other unstable molecules in the body that can damage cells if they accumulate in large amounts [7].

The agro-climatic condition of Bangladesh is suitable for pests and diseases infestation during the production and storage of vegetables, which considerably decreases the yield and quality of agricultural produce [4]. So, pesticide application is an essential part of modern agriculture, as it significantly reduces yield losses and maintains the quality of fruits and vegetables by controlling pests and diseases infestation [8]. In contrast, the indiscriminate application of pesticides by unqualified persons means that only a small portion of applied pesticides reach the targeted species; residues enter the food chain and adversely impact the non-target biota $[9,10]$. Moreover, the scenario of pesticide application in Bangladesh is more severe than in other developing countries. Several reports have demonstrated that farmers unintentionally spray pesticides in their vegetable fields on each alternate day or sometimes every day due to the lack of knowledge and unavailability of sustainable alternatives [11-13]. Furthermore, pesticide adulteration in terms of active ingredients is another shortcoming for safe food production in Bangladesh [11,14,15]. Researchers found that some of the marketed pesticide brands in Bangladesh contain less active ingredients than the required doses, whereas some contained no active ingredients at all, which is one of the reasons for the overuse of pesticides [11,14,16-19]. Accordingly, pests (insect, pathogens, and weeds) have become resistant to those specific pesticides due to the repeated use of adulterated pesticides [11,14]. Moreover, the extensive use of adulterated pesticide is accountable for the deposition of more toxic inert ingredient/carrier materials to soil, environment, and food matrices $[9,20]$.

The presence of pesticide residues in fresh fruits and vegetables raises serious health concerns for consumers [21]. So, the identification and quantification of pesticides in the food matrix are becoming a public interest [22,23]. Moreover, studying the health risks associated with the consumption of pesticide-contaminated vegetables in the southern part of Bangladesh, particularly in the Barishal District, is seldom given attention. Thus, research is greatly warranted to determine the actual scenario of pesticide residues present in the vegetables of Barishal district of Bangladesh and their associated risks to consumer health. In this perspective, the present study aims to quantify the level of pesticide residues present in country bean and eggplant available in the local markets of Barishal district, Bangladesh, for human consumption to create awareness in the general public and policymakers to take the necessary actions to minimize the risks of human health.

\section{Materials and Methods}

\subsection{Sample Collection and Preparation}

A total of $60(n=60)$ fresh vegetable samples (30 country bean and 30 eggplant samples) were collected from the major five markets (Rupatoli, Sagardi, Chowmatha, Notullabad, and Notun Bazar) of Barishal District in Bangladesh for this study (Figure 1). Six samples of country bean and six samples of eggplant were collected from every single market. The samples of each vegetables weighed $1.0 \mathrm{~kg}$ were collected in individual clean, transparent, airtight, and correctly labelled polyethylene bags. The collected samples were transported to the Pesticide Analytical Laboratory (ISO Accredited Laboratory), Pesticide Research and Environmental Toxicology Section, Entomology Division, Bangladesh Agricultural Research Institute (BARI), Gazipur, Bangladesh, on the day of collection. Each sample unit 
was cut into small pieces, mixed thoroughly, and stored in a refrigerator at $-20{ }^{\circ} \mathrm{C}$ until the extraction and cleanup process started.

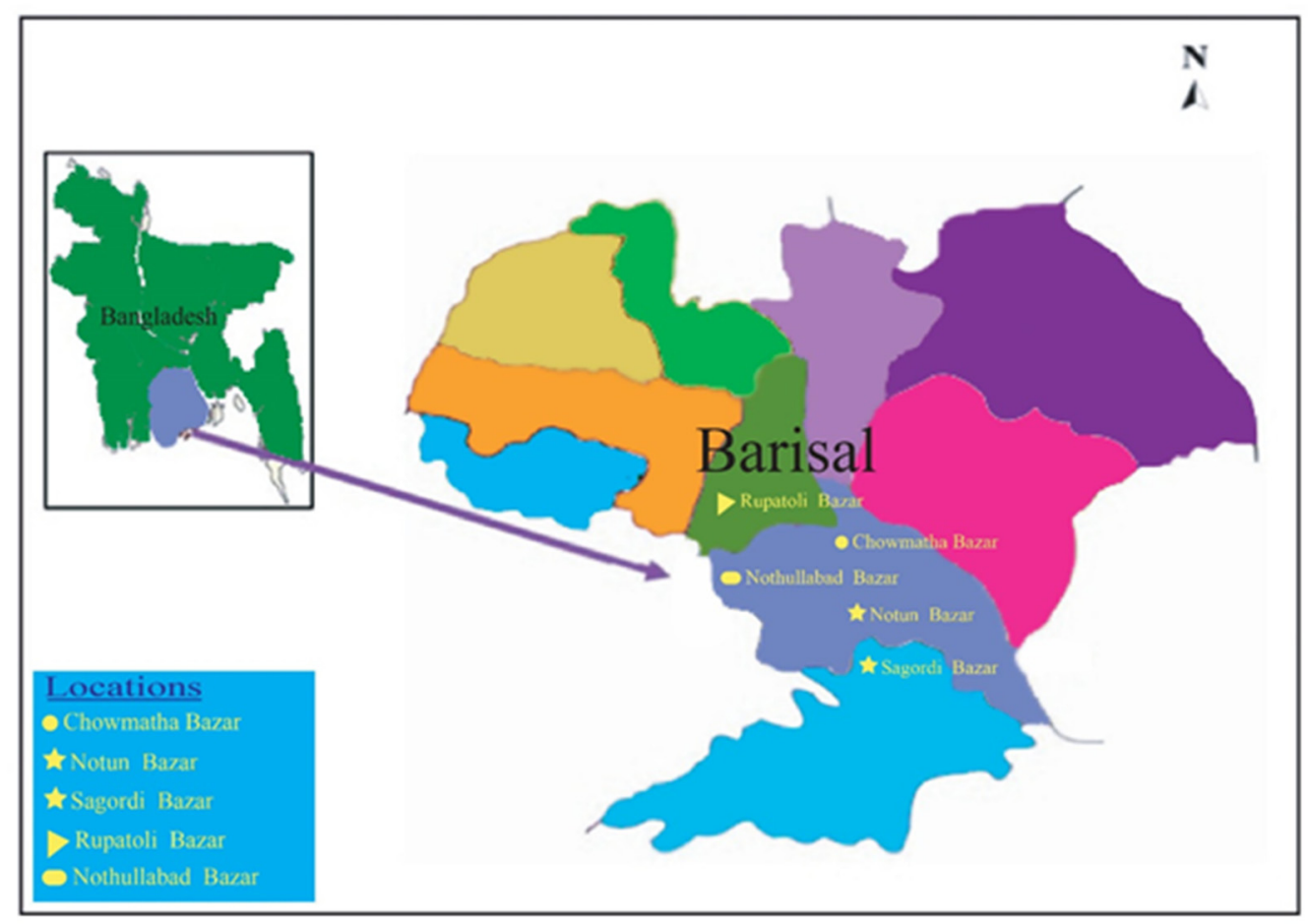

Figure 1. Map showing different sampling locations in the Barishal district, Bangladesh.

\subsection{Chemicals and Reagents}

Analytical grade ( $>99.6 \%$ purity) acetamiprid, cypermethrin, lambda-cyhalothrin, and thiram were obtained from Sigma-Aldrich (St. Louis, MO, USA) via Bangladesh Scientific Pvt. Ltd. Dhaka, Bangladesh. Other chemicals, including methanol, acetone, gradient grade acetonitrile, sodium chloride $(\mathrm{NaCl})$, anhydrous magnesium sulphate $\left(\mathrm{MgSO}_{4}\right)$, and primary secondary amine (PSA) were purchased from Bangladesh Scientific Pvt. Ltd. Dhaka, Bangladesh. The selection of pesticides was based on the information available in the literature, pesticide retailers, farmers, and the Department of Agricultural Extension, Bangladesh.

\subsection{Preparation of Pesticide Standard Solution}

Certified reference material (CRM) of acetamiprid, cypermethrin, lambda-cyhalothrin, and thiram were prepared separately in acetonitrile $(\mathrm{MeCN})$ at a concentration of $1000 \mathrm{mg} / \mathrm{L}$, and were stored at $-20^{\circ} \mathrm{C}$ until use. A mixed standard solution of $50 \mathrm{mg} / \mathrm{L}$ in $\mathrm{MeCN}$ containing all of the aforementioned pesticides was prepared by adding the appropriate volume of each stock solution into a $50 \mathrm{~mL}$ volumetric flask, and the volume was made up by adding acetone. An intermediate mixed standard solution of $10 \mathrm{mg} / \mathrm{L}$ in $\mathrm{MeCN}$ was prepared from the mixed standard solution of $50 \mathrm{mg} / \mathrm{L}$. Then, working standard solutions of $0.1,0.2,0.5,1.0,2.0,3.0$, and $5.0 \mathrm{mg} / \mathrm{L}$ in MeCN were prepared by transferring the appropriate amount from a $10 \mathrm{mg} / \mathrm{L}$ intermediate mixed standard solution into 10 separate $10-\mathrm{mL}$ volumetric flasks. All the standard solutions were kept in a freezer at $-20{ }^{\circ} \mathrm{C}$ until use. Matrix-matched standard for preparing the calibration curve was made by adding multiple standard working solutions in the blank extracts of both matrices separately to reach the desired concentrations $(0.01,0.02,0.05,0.1,0.2,0.3$, and $0.5 \mathrm{mg} / \mathrm{kg})$ and stored at $-20^{\circ} \mathrm{C}$. 


\subsection{Extraction and Clean Up}

In this study, the modified QuEChERS extraction technique was used to extract and clean up the collected vegetable samples [24]. The chopped vegetable samples were ground using a blender. A representative $10 \mathrm{~g}$ portion of the thoroughly homogenized sample was taken in a $50 \mathrm{~mL}$ polypropylene centrifuge tube containing $10 \mathrm{~mL}$ of $\mathrm{MeCN}$, and was shaken vigorously for $30 \mathrm{~s}$ using a vortex mixer. Then, $4 \mathrm{~g}$ of anhydrous $\mathrm{MgSO}_{4}$ and $1 \mathrm{~g}$ of $\mathrm{NaCl}$ were added into the centrifuge tube, which was immediately shaken for $1 \mathrm{~min}$ to prevent the formation of magnesium sulphate aggregates, and was centrifuged for $5 \mathrm{~min}$ at $1957 \times g$ (Sigma-3K30, Germany). An aliquot of $3 \mathrm{~mL}$ of the MeCN layer was transferred into a $15 \mathrm{~mL}$ centrifuge tube containing $600 \mathrm{mg}$ anhydrous $\mathrm{MgSO}_{4}$ and $120 \mathrm{mg}$ PSA. Then, it was thoroughly mixed for $30 \mathrm{~s}$ using a vortex mixer and centrifuged for $5 \mathrm{~min}$ at $1957 \times \mathrm{g}$. After centrifugation, a $1 \mathrm{~mL}$ supernatant was filtered with a $0.2 \mu \mathrm{m}$ PTFE filter and taken in a clean GC vial for further analysis.

\subsection{Instrumental Analysis}

The concentrated extracts were subjected to analysis by GC-2010 (Shimadzu Corporation, Japan) with an electron capture detector (ECD) for the detection of three insecticides (acetamiprid, cypermethrin, and lambda-cyhalothrin) and one fungicide (thiram). The capillary column was Rtx-CLPesticides 2 , with a length of $30 \mathrm{~m}$, ID of $0.32 \mathrm{~mm}$, and film thickness of $0.25 \mu \mathrm{m}$. Nitrogen was used as a carrier and make up gas for GC-ECD. The identification of the suspected pesticide was performed using the peak retention times in the samples compared to those of the peaks in the pure analytical standards. The instrumental conditions are described in Table S1.

\subsection{Quality Assurance Procedure}

The experiment was validated based on the specificity, linearity, coefficient of determination $\left(\mathrm{R}^{2}\right)$, accuracy, precision and limit of quantification (LOQ). The specificity was determined by the specific retention time on the chromatogram for a particular pesticide. The linearity and $\mathrm{R}^{2}$ value were calculated continuously using the standard fortified solutions of each pesticide at concentration levels ranging between 0.01 to $0.5 \mathrm{mg} / \mathrm{kg}$. The accuracy and precision were performed at a fortification level of $0.1 \mathrm{mg} / \mathrm{kg}$ for both of the selected matrices. The average recoveries of the selected pesticides ranged from 80 to $96 \%$, with RSD $\leq 10 \%$ for eggplant, and it was $88-110 \%$ with RSD $\leq 9 \%$ for country bean. The LOQ was calculated as the lowest detection level for each pesticide, which also helped to measure the sensitivity of the method. The linearity, $R^{2}$ value, and LOQ were measured in an external standard solution using the peak areas obtained by the GC-ECD analysis. The linear regression equation, $\mathrm{R}^{2}$ values, and LOQ are given in Table S2. The standard curve showed that the linearity was excellent, with $\mathrm{R}^{2}$ value ranging from $0.9931-0.9998$. The LOQs were $0.01 \mathrm{mg} / \mathrm{kg}$, indicating the high sensitivity of this method. The proposed method was applied to the external standard solution for assessing its specificity. The specificity of four selected pesticides was performed by comparing the retention times of each pesticide presented in a typical chromatogram obtained by GC-ECD using an analysis of the external added standard solution and matrix solvent.

\subsection{Health Risk Assessment}

The health risk assessment is the estimation of to what extent a consumer's health would be at risk by consuming pesticide-contaminated vegetables. The health risks from both acute and chronic exposure associated with the intake of pesticide is considered. The acute health risk to a consumer $(\mathrm{aHI})$ is measured using the estimated short-term intake and the acute reference dose of a pesticide. The following equation can express the acute health risk to the consumer (aHI) [25]:

$$
a H I=\frac{E S T I}{a R f D} \times 100 \%
$$




$$
E S T I=h R L \times \frac{F C}{B W}
$$

where $\operatorname{aRfD}(\mathrm{mg} / \mathrm{kg} /$ day) is the acute reference dose of a particular pesticide, ESTI ( $\mathrm{mg} / \mathrm{kg} /$ day) is the estimated short-term intake of the pesticide, $h R L$ is the highest residue level, FC is food consumption, and $B W(\mathrm{~kg})$ is body weight. The exposed consumer is considered safe when the estimated short-term intake of a pesticide residue does not exceed the $a R f D$, while $a R f D$ is the outcome of a complete hazard characterization of a pesticide compound. The health risk assessment is considered acceptable when the exposure values of the assessed consumer do not exceed $100 \%$ of the $a$ RfD.

The chronic health risk/hazard quotient to consumer $(H Q)$ is measured to predict the long-term health effects of pesticides due to the consumption of contaminated vegetables. The chronic health risk from a particular pesticide can be expressed as $H Q$ [26]:

$$
\begin{aligned}
& H Q=\frac{E D I}{A D I} \times 100 \% \\
& E D I=m R L \times \frac{F C}{B W}
\end{aligned}
$$

where $E D I$ ( $\mathrm{mg} / \mathrm{kg} /$ day) is the estimated daily intake of a pesticide, $A D I(\mathrm{mg} / \mathrm{kg} / \mathrm{day})$ is the acceptable chronic daily of the pesticide, and $\mathrm{mRL}$ is the mean residue level. Usually, $H Q<1$ indicates that the exposed consumer is safe from the potential adverse effects of the pesticide, whereas $H Q>1$ represents the detrimental health effects in the exposed consumer [26]. For the appropriate calculation, the $a R f D$ and $A D I(\mathrm{mg} / \mathrm{kg} /$ day) of a person (60 kg adult and $10 \mathrm{~kg}$ children) for acetamiprid, cypermethrin, lambda-cyhalothrin, and thiram pesticides were obtained from the Joint FAO/WHO Meeting on Pesticide Residues (JMPR) database [25]. According to $\mathrm{FAO} / \mathrm{WHO}$, the average national consumption of $23 \mathrm{~g}$ of leafy vegetables, $89 \mathrm{~g}$ of non-leafy vegetables, and $14 \mathrm{~g}$ of fruit (a total of $126 \mathrm{~g}$ of fruit and vegetables) are consumed per capita per day in Bangladesh [27].

\subsection{Statistical Analysis}

The level of pesticide residues in the collected samples was analyzed and calculated in $\mathrm{mg} / \mathrm{kg}$ automatically using the Shimadzu GC software. The experimental data obtained were processed using Microsoft Excel (Excel, 2016).

\section{Results and Discussion}

A total of 60 vegetable samples $(n=60)$, including 30 country bean and 30 eggplant samples, collected from five different markets (Rupatoli, Sagardi, Chowmatha, Notullabad, and Notun Bazar) of the Barishal District were analyzed to quantify the residues of neonicotinoid insecticide (acetamiprid), synthetic pyrethroid insecticides (cypermethrin and lambda-cyhalothrin), and dithiocarbamate fungicide (thiram) to ensure food safety. A sample was considered positive when the pesticide residue levels were above the LOQ. As shown in Table 1, nine vegetable samples were confirmed positive for pesticide residues, whereas two samples (B-10 and E-23) were found to be above the EU-MRLs. Two pesticides, acetamiprid and cypermethrin, were detected in both country bean and eggplant samples. 
Table 1. The level of residues $(\mathrm{mg} / \mathrm{kg}$ ) of different pesticides found in the analyzed country bean (B) and eggplant (E) samples $(n=60)$; six samples $(n=6)$ of each vegetable collected from every location.

\begin{tabular}{ccccc}
\hline Area of Collection & Sample ID & Detected Pesticide & Level of Residue (mg/kg) & EU-MRLs (mg/kg) \\
\hline \multirow{2}{*}{ Rupatoli Bazar } & B-4 & Acetamiprid & 0.341 & 0.6 \\
& E-6 & Cypermethrin & 0.156 & 0.5 \\
Sagardi Bazar & B-10 & Acetamiprid & 0.672 & 0.6 \\
Chowmatha Bazar & E-11 & Cypermethrin & 0.090 & 0.5 \\
Notun Bazar & B-18 & Acetamiprid & 0.278 & 0.6 \\
Nothullabad Bazar & B-17 & Cypermethrin & 0.071 & 0.5 \\
& E-23 & Cypermethrin & 0.116 & 0.7 \\
\hline
\end{tabular}

\subsection{Pesticide Residues in Country Bean}

The concentrated extracts of the bean samples collected from different markets of the Barishal District were analyzed using GC-ECD with the pre-set parameters (Table S1). Thirty $(n=30)$ samples of country bean were analyzed to determine the presence of leftover residues of four pesticides (acetamiprid, cypermethrin, lambda-cyhalothrin, and thiram). Out of the 30 samples, five (17\% of the total number of samples) contained residues of acetamiprid and cypermethrin, and 25 samples ( $83 \%$ of the total number of samples) had no detectable residues of the considered pesticides. Acetamiprid and cypermethrin were the most frequently used pesticides that were identified in country bean samples, whereas no residues of thiram and lambda-cyhalothrin were identified. The findings of the present investigation agreed with the results of Islam et al., 2019, and Nahar et al., 2020 [28,29]; they found that among the 65 analyzed samples, 8 ( $12.3 \%$ of the total number of samples) were contaminated with pesticide residues and all of the contaminated samples contained residues above EU-MRL, collected from different markets of Savar, Bangladesh. The current outcomes are also supported by the findings of Kumar et al., 2008 [6], who reported that 15 out of 42 samples (about $35.71 \%$ ) of eggplant, cauliflower, and country bean contained no residues of the considered pesticides collected from fields and markets in the Narsingdi District of Bangladesh.

In this study, six samples of country bean were obtained from the Rupatoli Bazar; among them, one sample (B-04) contained residue of acetamiprid at a level of $0.341 \mathrm{mg} / \mathrm{kg}$, which was below the EU-MRL ( $0.6 \mathrm{mg} / \mathrm{kg}$ ) (Table 1 and Figure S1). The other five samples had no detectable pesticide residues. According to the retailer's opinion, the contaminated bean sample (B-04) was collected from the Lakutia area. Among the six samples collected from the Sagardi Bazar, only one sample (B-10) contained residue of acetamiprid $(0.672 \mathrm{mg} / \mathrm{kg})$ that was above EU-MRL $(0.6 \mathrm{mg} / \mathrm{kg})$, and the other five samples had no detectable pesticide residues (Table 1 and Figure S2). Based on the retailer's opinion, this contaminated bean sample (B-10) originated from the Rajapur area. For one sample (B-18) from the six country bean samples derived from the Barguna area and taken from Chowmatha Bazar, the residue of acetamiprid was quantified at $0.278 \mathrm{mg} / \mathrm{kg}$, which was below the EU-MRL $(0.6 \mathrm{mg} / \mathrm{kg}$ ) (Table 1 and Figure S3). The cypermethrin residue was also found at $0.116 \mathrm{mg} / \mathrm{kg}$ in one sample from the Pirojpur area (B-21) of country bean out of the six collected from the Notun Bazar, which was below the EU-MRL $(0.7 \mathrm{mg} / \mathrm{kg})$ (Table 1 and Figure S4). In the Nothullabad Bazar samples, only one sample, which originated from the Swarupkathi area (B-28), contained residue of cypermethrin, and the other five samples had no detectable pesticide residues. The level of detected residue was $0.081 \mathrm{mg} / \mathrm{kg}$, which was lower than the EU-MRL $(0.7 \mathrm{mg} / \mathrm{kg}$ ) (Table 1 and Figure S5).

\subsection{Pesticide Residues in Eggplant}

In the case of eggplant, 30 samples $(n=30)$ of eggplant were analyzed to find out pesticide residues to ensure food safety. Out of the 30 samples, four samples ( $13 \%$ of the total number) contained pesticide residues, and 26 samples ( $87 \%$ of the total number) had 
no detectable residues of the considered pesticides. Both acetamiprid and cypermethrin were identified in the eggplant samples obtained from the investigated areas. In contrast, leftover residues of thiram and lambda-cyhalothrin were not found in those samples collected from the five markets. The outcome of the present study is in good agreement with the outcome of Nahar et al., 2020, and Rashid et al., 2018 [5,28]; they found that among 50 analyzed samples, 11 ( $22 \%$ of the total number of the samples) contained residues of diazinon, dimethoate, quinalphos, and chlorpyrifos in the eggplant collected from the Mymensingh District of Bangladesh, of which, two had multiple pesticide residues and five contained residues above the EU-MRLs. This study is also supported by the findings of Hasan et al., 2017 [30], where, out of 50 analyzed samples, ten samples (20\%) had residues of dimethoate and quinalphos in country bean collected from different markets of the Dhaka District of Bangladesh.

Six samples of eggplant from the Bhola area were collected from the Rupatoli Bazar; among them, one sample (E-06) contained residue of cypermethrin at $0.156 \mathrm{mg} / \mathrm{kg}$, which was lower than the EU-MRL $(0.5 \mathrm{mg} / \mathrm{kg}$ ) (Table 1 and Figure S6). In contrast, the other five samples contained no detectable residues of the selected pesticides. Among the six samples of eggplant collected from the Sagordi Bazar, one sample (E-11) contained residues of pesticide at $0.090 \mathrm{mg} / \mathrm{kg}$, and the level was below EU-MRL ( $0.5 \mathrm{mg} / \mathrm{kg}$ ) (Table 1 and Figure S7). According to the retailer, these samples came to this market from the Bhandaria area. One eggplant sample (E-17) out of six collected from the Chowmatha Bazar (the source of those samples was the Patuakhali area) contained residues of cypermethrin at $0.071 \mathrm{mg} / \mathrm{kg}$, which was lower than the EU-MRL (0.5 mg/kg) (Table 1 and Figure S8). Six samples of eggplant were collected from the Notun Bazar (came from the Charfashion area); among them, one sample (E-23) contained residue of acetamiprid $(0.389 \mathrm{mg} / \mathrm{kg})$ that was higher than the EU-MRL $(0.2 \mathrm{mg} / \mathrm{kg})$ (Table 1 and Figure S9). The case of the six samples of eggplant collected from the Nothullabad Bazar had no detected residues of the considered pesticides.

All of the analyzed samples indicated that approximately $83 \%$ and $87 \%$ of country bean and eggplant samples contained no detectable pesticide residues, respectively. In contrast, around $17 \%$ and $13 \%$ of country bean and eggplant samples, respectively, contained residues of acetamiprid and cypermethrin; among the contaminated samples, $20 \%$ and $25 \%$ had residues above EU-MRL, respectively. In contrast, the survey reports indicated that farmers used high doses of pesticides repeatedly in the investigated areas, which is of serious concern to the scientific community [11-13]. The research outcome is inconsistent with farmer's pesticide usage patterns for vegetables in this region. However, the current findings support the claim of pesticide adulteration in terms of an active ingredient known to be used in the investigated areas for vegetable production. The marketed brands of pesticides might have less quantity of active ingredients than the recommended dose or no active ingredient at all. Consequently, the data obtained from the purity analysis of acetamiprid, cypermethrin, lambda-cyhalothrin, and thiram were 20.0, 0.0-100, 2.5, and $17-20 \%$, respectively, which were collected from the dealers or retailers of Bogura, Chittagong, Chuadunga, Comilla, Dinajpur, Faridpur, Gazipur, Jamalpur, Jessore, Kushtia, Meherpur, Mymensing, Norshingdi, Rajshahi, and Rangpur Districts of Bangladesh (Table 2) [11,14,16-19,31]. Thus, farmers spray pesticides in their agricultural field on each alternate day or sometimes every day to protect their crops from pest and diseases infestation [11-13]. The indiscriminate and overuse of these adulterated pesticides is not desired, as they deposit more toxic additives/carrier materials to soil, environment, and food matrices [9]. Besides, pests become resistant to those pesticides due to the overuse of adulterated pesticides $[11,14]$. 
Table 2. Percentage of active ingredient present in some marketed brands of pesticides.

\begin{tabular}{|c|c|c|c|c|}
\hline Pesticides Name & Collected District & Location & Purity (\% a.i) & References \\
\hline Acetamiprid 20 SP & $\begin{array}{l}\text { Kushtia, Meherpur, Chuadunga, } \\
\text { Rajshahi, Dinajpur, Jamalpu, and } \\
\text { Mymensigh }\end{array}$ & $\begin{array}{c}\text { Dealers/local } \\
\text { market/retailers }\end{array}$ & 20.0 & [19] \\
\hline Cypermethrin10 EC & $\begin{array}{c}\text { Bogra, Chittagong, Comilla, } \\
\text { Dinajpur, Gazipur, Jessore, } \\
\text { Jamalpur, Mymensing, } \\
\text { Narshingdi, Rajshahi, and } \\
\text { Rangpur }\end{array}$ & $\begin{array}{c}\text { Dealers/local } \\
\text { market/retailers }\end{array}$ & $0.0-100.0$ & {$[11,12,15]$} \\
\hline $\begin{array}{l}\text { Lambda-cyhalothrin } \\
\text { (Karate 2.5 EC or Reeva } \\
2.5 \mathrm{EC})\end{array}$ & $\begin{array}{c}\text { Bogra, Rajshahi, Jessore, } \\
\text { Narshingdi, Comilla, Jamalpur, } \\
\text { and Gazipur }\end{array}$ & $\begin{array}{c}\text { Dealers/local } \\
\text { market/retailers }\end{array}$ & 2.5 & {$[16,17]$} \\
\hline Thiram & Faridpur and Gazipur & $\begin{array}{c}\text { Dealers/local } \\
\text { market/retailers }\end{array}$ & 17.0-20.0 & {$[17,18]$} \\
\hline
\end{tabular}

\subsection{Human Health Risk Assessment}

The human health risk associated with pesticide residues in country bean and eggplant samples were assessed based on the aHI and HQ, and are represented in Table 3 and Figure 2. The acute and chronic health risks of pesticides were calculated only for those samples that contained residues above or close to the EU-MRL. The calculated aHI values of acetamiprid and cypermethrin in both of the analyzed vegetables for adults and children ranged from $0.430-0.997$ and 2.581-5.980, respectively (Table 3 ). The calculated aHI values of both pesticides for adults did not exceed $100 \%$ of the aRfD, indicating a negligible acute or short-term health risk via the consumption of pesticide-contaminated vegetables. In contrast, the assessed aHI values for children showed the potential threat to their health, as the values significantly exceeded the acceptable limit, while acetamiprid $(\mathrm{aHI}=5.980)$ showed a higher risk factor compared with cypermethrin $(\mathrm{aHI}=2.581)$.

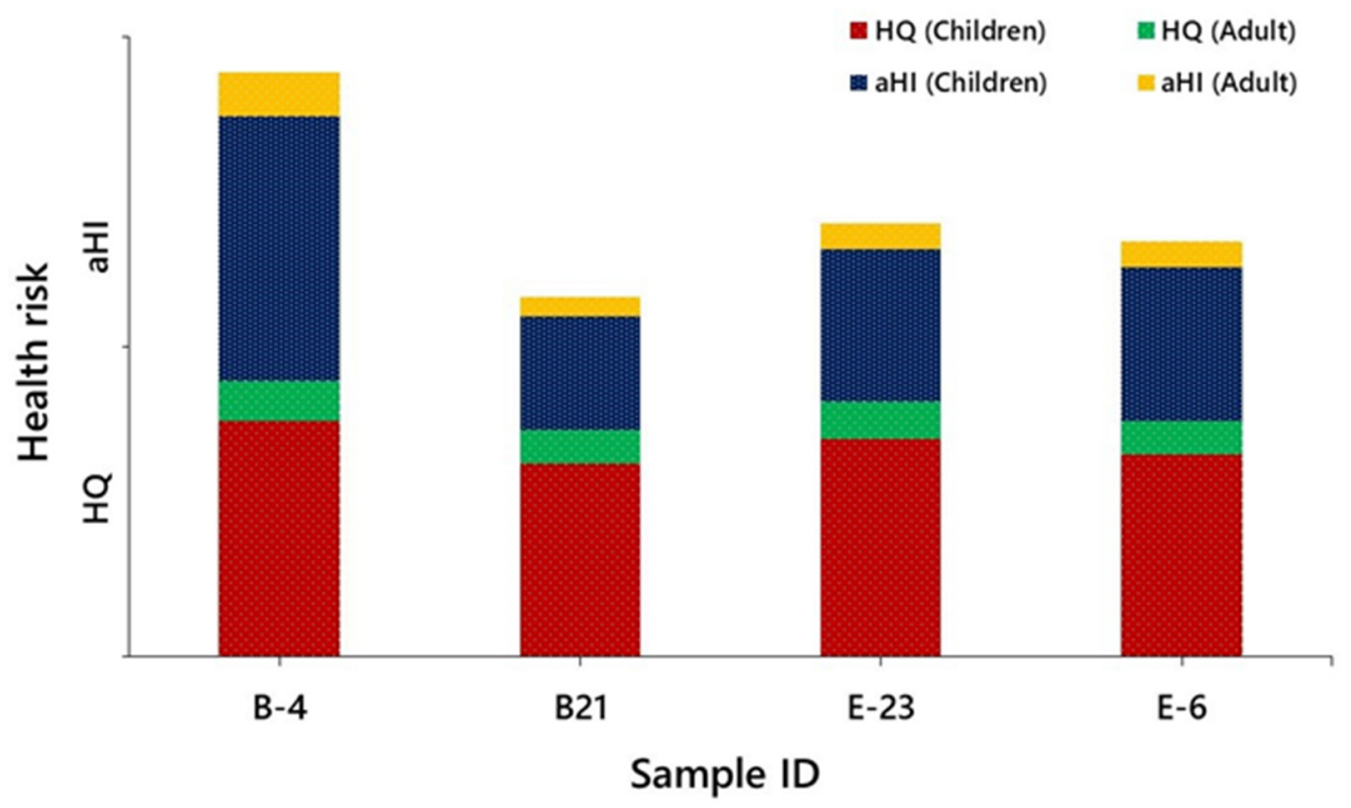

Figure 2. Non-cancer acute health risk (aHI) and chronic hazard quotient (HQ) values for children and adults due to the likely consumption of pesticide-contaminated green vegetables. B = country bean; E = eggplant; six samples $(n=6)$ of each vegetable collected from every location. 
Table 3. Non-cancer acute and chronic health hazards for adults and children due to the consumption of pesticidecontaminated green vegetables.

\begin{tabular}{|c|c|c|c|c|c|c|c|c|c|c|}
\hline \multicolumn{6}{|c|}{ Short-Term Risk } & \multicolumn{5}{|c|}{ Long-Term Risk } \\
\hline Insecticide & Sample ID & Location & $\begin{array}{c}\text { aRfD } \\
\text { (mg/kg } \\
\text { bw/day) }\end{array}$ & $\begin{array}{c}\text { ESTI } \\
\text { (mg/kg/day) }\end{array}$ & $\begin{array}{l}\mathrm{aHI} \\
(\%)\end{array}$ & $\begin{array}{c}\text { EDI } \\
\text { (mg/kg/day) }\end{array}$ & $\begin{array}{c}\text { ADI } \\
\text { (mg/kg/day) }\end{array}$ & HQ & Adults/Children & Effect \\
\hline \multicolumn{11}{|c|}{ Country bean (Lablab purpureus L.) } \\
\hline Acetamiprid & B-4 & $\begin{array}{c}\text { Rupatoli } \\
\text { Bazar }\end{array}$ & 0.1 & $\begin{array}{l}9.97 \times 10^{-4} \\
5.98 \times 10^{-3}\end{array}$ & $\begin{array}{l}0.997 \\
5.980\end{array}$ & $\begin{array}{l}6.23 \times 10^{-4} \\
3.74 \times 10^{-3}\end{array}$ & 0.07 & $\begin{array}{l}0.890 \\
5.340\end{array}$ & $\begin{array}{l}\text { Adults } \\
\text { Children }\end{array}$ & $\begin{array}{c}\text { Alarming } \\
\text { Yes }\end{array}$ \\
\hline Cypermethrin & B-21 & Notun Bazr & 0.04 & $\begin{array}{l}1.72 \times 10^{-4} \\
1.03 \times 10^{-3}\end{array}$ & $\begin{array}{l}0.430 \\
2.581 \\
\end{array}$ & $\begin{array}{l}1.46 \times 10^{-4} \\
8.77 \times 10^{-4}\end{array}$ & 0.02 & $\begin{array}{l}0.731 \\
4.383 \\
\end{array}$ & $\begin{array}{l}\text { Adults } \\
\text { Children }\end{array}$ & $\begin{array}{c}\text { Alarming } \\
\text { Yes }\end{array}$ \\
\hline \multicolumn{11}{|c|}{ Eggplant (Solanum melongena L.) } \\
\hline Acetamiprid & E-23 & $\begin{array}{l}\text { Notun } \\
\text { Bazar }\end{array}$ & 0.1 & $\begin{array}{l}5.77 \times 10^{-4} \\
3.46 \times 10^{-3}\end{array}$ & $\begin{array}{l}0.577 \\
3.462\end{array}$ & $\begin{array}{l}5.76 \times 10^{-4} \\
3.45 \times 10^{-3}\end{array}$ & 0.07 & $\begin{array}{l}0.822 \\
4.933\end{array}$ & $\begin{array}{l}\text { Adults } \\
\text { Children }\end{array}$ & $\begin{array}{c}\text { Alarming } \\
\text { Yes }\end{array}$ \\
\hline Cypermethrin & E-6 & $\begin{array}{c}\text { Rupatoli } \\
\text { Bazar }\end{array}$ & 0.04 & $\begin{array}{l}2.31 \times 10^{-4} \\
1.39 \times 10^{-3}\end{array}$ & $\begin{array}{l}0.579 \\
3.471\end{array}$ & $\begin{array}{l}1.52 \times 10^{-4} \\
9.15 \times 10^{-4}\end{array}$ & 0.02 & $\begin{array}{l}0.762 \\
4.574\end{array}$ & $\begin{array}{l}\text { Adults } \\
\text { Children }\end{array}$ & $\begin{array}{c}\text { Alarming } \\
\text { Yes }\end{array}$ \\
\hline
\end{tabular}

In the case of chronic or long-term health risk, based on the HQ values of the acetamiprid and cypermethrin, the residues in the vegetables for adults and children ranged from $0.731-0.890$ and 4.383-5.340, respectively (Table 3). In case of adults, the calculated $H Q$ values for both pesticides did not exceed the acceptable limit $(H Q<1)$, but all the values were close to 1.0, considered alarming for human health regarding the consumption of pesticide-contaminated vegetables. In contrast, the estimated $H Q$ values for children showed potential chronic health risks, as the values significantly exceeded the tolerable limit $(H Q>1)$, whereas acetamiprid $(H Q=5.340)$ indicated a higher risk factor compare with cypermethrin $(H Q=4.383)$. Thus, the estimated health risks of pesticide residues in the vegetables based on the aHI and $H Q$ was relatively higher for children than adults (Figure 2). It is noted that the vegetable samples were analyzed in the current study directly after collection without washing. However, some common practices might reduce the extent of pesticide residues, including washing, peeling, and cooking vegetables after purchasing [32-36]. Consequently, in the Bangladesh perspective, it is crucial for policymakers not to destroy these contaminated vegetables, as one-third of the population suffers from malnutrition due to insufficient food intake. Moreover, these samples are not allowed for international trade as fresh produce as they contain pesticide residues slightly above or below the EU-MRL.

\section{Conclusions}

The current research explores pesticide residue in the country bean and eggplant available in local markets for human consumption. The residues of acetamiprid and cypermethrin were found in $17 \%$ and $13 \%$ of country bean and eggplant samples, respectively; among them, $3 \%$ and $1 \%$ had residues of acetamiprid, which was above the EU-MRLs. None of the samples was found to contain thiram and lambda-cyhalothrin residues for both of the analyzed vegetables. From a public health viewpoint, pesticide residues above MRL pose a potential acute health risk, whereas residues below MRL may be responsible for long term chronic health effects in consumers. Moreover, the assessment of chronic non-cancer health risks, according to $\mathrm{aHI}$ and $\mathrm{HQ}$, confirms that pesticide residues in contaminated beans might pose a potential threat to children's health and an alarming threat for adults. Thus, farmers should be made aware of the recommended doses of pesticides during application to avoid overuse. Besides, pesticide adulteration must be monitored and stopped immediately through appropriate control measures. Eventually, routine testing considering active ingredients and additives or carrier materials of pesticides could be performed to ensure food safety.

Supplementary Materials: The following are available online at https:/ /www.mdpi.com/article/10 .3390 /agronomy11091804/s1. Figure S1: Chromatogram of acetamiprid found in one of the bean samples (B-04) collected from Rupatoli Bazar. Figure S2: Chromatogram of acetamiprid found 
in one of the bean samples (B-10) collected from Sagardi Bazar. Figure S3: Chromatogram of acetamiprid found in one of the bean samples (B-18) collected from Chowmatha Bazar. Figure S4: Chromatogram of cypermethrin found in one of the bean samples (B-21) collected from Notun Bazar. Figure S5: Chromatogram of cypermethrin found in one of the bean samples (B-28) collected from Nothullabad Bazar. Figure S6: Chromatogram of cypermethrin found in one of the eggplant samples (E-06) collected from Rupatoli Bazar. Figure S7: Chromatogram of cypermethrin found in one of the eggplant samples (E-11) collected from Sagardi Bazar. Figure S8: Chromatogram of cypermethrin found in one of the eggplant samples (E-17) collected from Chowmatha Bazar. Figure S9: Chromatogram of acetamiprid found in one of the eggplant samples (E-23) collected from Notun Bazar. Table S1: The instrumental conditions for GC-ECD. Table S2: Linear regression parameters and LOQ of the four selected pesticides in the external added standard solution.

Author Contributions: U.S.N.: methodology, data interpretation, validation, and preparation of original draft; M.S.I.K.: conceptualization, supervision, writing and editing; M.D.H.P.: supervision, writing, editing, and provided training and analytical support; I.M.M.: comprehensive writingreview and editing; N.B.: review and editing; A.P.: writing-review and editing; S.S.: review and editing; A.S.J.: writing-review and editing; M.A.H.: writing-review and editing. All authors have read and agreed to the published version of the manuscript.

Funding: This research received no external funding.

Acknowledgments: The authors are grateful to Sher-e-Bangla Agricultural University Research System (SAURES), Bangladesh, for partial financial support to conduct this research work. The authors are thankful to Bangladesh Agricultural Research Institute for providing the laboratory facilities to analyze the samples in the Pesticide Analytical Laboratory, BARI, Gazipur, Bangladesh, and the authors are also thankful to Universiti Putra Malaysia (UPM), Malaysia, for their cooperation to publish the article.

Conflicts of Interest: The authors declare there are no conflict of interest.

\section{References}

1. Kumari, B.; Madan, V.; Kumar, R.; Kathpal, T. Monitoring of seasonal vegetables for pesticide residues. Environ. Monit. Assess. 2002, 74, 263-270. [CrossRef] [PubMed]

2. Miah, M.; Barman, N.; Alam, M.; Yesmin, K.; Ahmad, M. Effectiveness of some IPM packages consisting of chemical and non chemical components for suppressing pod borer and aphid in summer country bean. J. Environ. Sci. Nat. Resour. 2017, 10, 109-115. [CrossRef]

3. Jadhav, B.; Patil, B.; Patil, V. Effects of triacontanol on lablab-bean and Indian mustard. Ind. J. Agric. Sci. 1987, 57, 56-58.

4. Parven, A.; Khan, M.S.I.; Prodhan, M.D.H.; Venkateswarlu, K.; Mallavarapu, M.; Islam, M. Human health risk assessment through quantitative screening of insecticide residues in two green beans to ensure food safety. J. Food Compos. Anal. 2021, 104121. [CrossRef]

5. Rashid, M.; Hasan, M.; Matin, M. Socio-economic performance of BT eggplant cultivation in Bangladesh. Bangladesh J. Agric. Res. 2018, 43, 187-203. [CrossRef]

6. Kumar, G.; Meena, B.; Kar, R.; Tiwari, S.K.; Gangopadhyay, K.; Bisht, I.; Mahajan, R. Morphological diversity in brinjal (Solanum melongena L.) germplasm accessions. Plant Gen. Resour. 2008, 6, 232. [CrossRef]

7. Aktar, M.A.; Khatun, R.; Prodhan, M.D.H. Determination of pesticide residues in eggplant using modified quechers extraction and gas chromatography. Int. J. Agron. Agric. Res. 2017, 11, 22-31.

8. Meftaul, I.M.; Venkateswarlu, K.; Dharmarajan, R.; Annamalai, P.; Megharaj, M. Pesticides in the urban environment: A potential threat that knocks at the door. Sci. Total Environ. 2020, 711, 134612. [CrossRef]

9. Meftaul, I.M.; Venkateswarlu, K.; Dharmarajan, R.; Annamalai, P.; Asaduzzaman, M.; Parven, A.; Megharaj, M. Controversies over human health and ecological impacts of glyphosate: Is it to be banned in modern agriculture? Environ. Pollut. 2020, 263, 114372. [CrossRef]

10. Meftaul, M.I.; Venkateswarlu, K.; Rajarathnam, D.; Annamalai, P.; Megharaj, M. Sorption-desorption of dimethoate in urban soils and potential environmental impacts. Environ. Sci Process. Impacts 2020, 22, 2256-2265. [CrossRef]

11. Begum, A.; Akon, M.W.; Ahmed, M.S.; Alam, S.N. Purity analysis of nine pesticides collected from eight locations in Bangladesh. Bangladesh J. Agric. Res. 2016, 41, 685-694. [CrossRef]

12. Ahmed, M.S.; Sarder, M.; Hoque, M.; Kabir, K. A survey on the pattern of insecticidal usage for the protection of the brinjal (Solanum melongina L.) from the attack of insect pests in Jessore. Bangladesh J. Zool. 2005, 33, 57.

13. Kabir, K.; Baksh, M.; Rouf, F.; Karim, M.; Ahmed, A. Insecticide usage pattern on vegetables at farmers' level of jessore region in Bangladesh: A survey finding. Bangladesh J. Agric. Res. 1996, 21, 241-254. 
14. Ahmed, M.S.; Sardar, M.M.A.; Ahmad, M.; Kabir, K.H. Quantification of purity of some frequently used insecticides in vegetables insect pests. Asian J. Med. Biol. Res. 2017, 3, 267-275. [CrossRef]

15. Afroze, M.; Prodhan, M.D.H.; Begum, A.; Ahmed, M.S.; Sarker, D. Purity Analysis of Different Brands of Marketed Pesticides. 2020. Available online: https://www.Researchgate.Net/publication/347974924 (accessed on 25 January 2021).

16. Chowdhury, M.A.; Hasan, M.S. Hand book of agricultural technology. In Bangladesh Agricultural Research Council \& Asian Food and Agriculture Cooperation Initiative; Bangladesh Agricultural Research Council: Dhaka, Bangladesh, $2013 ;$ pp. 74-92.

17. Chowdhury, M.; Rahman, M.; Miaruddin, M.; Khan, M.; Rahman, M. Assessment of pesticides and ripening chemicals used in selected vegetables at different locations of Bangladesh. Bangladesh J. Agric. Res. 2019, 44, 261-279. [CrossRef]

18. Miah, S.; Shahjahan, A.K.M.; Sharma, N.R.; Ahmed, H.U. Field evaluation of fungisides for rice sheath blight control. Bangladesh J. Bot. 1994, 23, 239-244.

19. Raza, M.S.; Rahman, M.A.; Rahaman, K.M.M.; Juliana, F.M.; Hossain, S.; Rahman, A.; Hossain, K.; Alam, M.J.; Asaduzzaman, M. Present status of insecticides use for the cultivation of brinjal in Kushtia region, Bangladesh. Int. J. Eng. Sci. Invent. 2018, 7, 44-51.

20. Meftaul, I.M.; Venkateswarlu, K.; Dharmarajan, R.; Annamalai, P.; Megharaj, M. Movement and fate of 2,4-D in urban soils: A potential environmental health concern. ACS Omega 2020, 5, 13287-13295. [CrossRef] [PubMed]

21. Jallow, M.F.; Awadh, D.G.; Albaho, M.S.; Devi, V.Y.; Ahmad, N. Monitoring of pesticide residues in commonly used fruits and vegetables in Kuwait. Int. J. Environ. Res. Public Health 2017, 14, 833. [CrossRef]

22. Villaverde, J.; Sevilla-Morán, B.; López-Goti, C.; Alonso-Prados, J.; Sandín-España, P. QSAR/QSPR models based on quantum chemistry for risk assessment of pesticides according to current European legislation. SAR QSAR Environ. Res. 2020, 31, 49-72. [CrossRef]

23. Villaverde, J.J.; Sevilla-Morán, B.; Sandín-España, P.; Lopez-Goti, C.; Alonso-Prados, J.L. Challenges of biopesticides under the European regulation (EC) No. 1107/2009: An overview of new trends in residue analysis. Studies Natur. Prod. Chem. 2014, 43, 437-482.

24. Prodhan, M.D.H.; Papadakis, E.N.; Papadopoulou-Mourkidou, E. Determination of multiple pesticide residues in eggplant with liquid chromatography-mass spectrometry. Food. Anal. Methods 2015, 8, 229-235. [CrossRef]

25. JMPR, Pesticide Residues in Food: Joint FAO/WHO Meeting on Pesticide Residues. WHO Pesticide Residues Series. Rome, Italy. 2006. Available online: http:/ / apps.Who.Int/iris/bitstream/10665/43624/1/9241665203_eng.Pdf (accessed on 14 January 2021).

26. Meftaul, I.M.; Venkateswarlu, K.; Annamalai, P.; Parven, A.; Megharaj, M. Glyphosate use in urban landscape soils: Fate, distribution, and potential human and environmental health risks. J. Environ. Manag. 2021, 292, 112786. [CrossRef] [PubMed]

27. Haque, M.M.; Hassan, M.A.; Islam, K.; Bhuiyan, M.R.; Shahi, M.S.J.R.; Lipi, R.P. Diet intake pattern and nutritional status of rural population in Bangladesh. Chattagram Maa-O-Shishu Hosp. Med. College J. 2014, 13, 51-54. [CrossRef]

28. Nahar, K.M.; Khan, M.S.I.; Habib, M.; Hossain, S.M.; Prodhan, M.D.H.; Islam, M.A. Health risk assessment of pesticide residues in vegetables collected from northern part of Bangladesh. Food Res. 2020, 4, 2281-2288. [CrossRef]

29. Islam, M.A.; Ullah, A.; Habib, M.; Chowdhury, M.T.I.; Khan, M.S.I.; Kaium, A.; Prodhan, M.D.H. Determination of major organophosphate pesticide residues in cabbage collected from different markets of Dhaka. Asia Pac. Environ. Occup. Health J. 2019, 5, 30-35.

30. Hasan, R.; Prodhan, M.D.H.; Rahman, S.M.M.; Khanom, R.; Ullah, A. Determination of organophosphorus insecticide residues in country bean collected from different markets of Dhaka. J. Environ. Anal. Toxicol. 2017, 7, 1000489. [CrossRef]

31. Kabir, K.H.; Rahman, M.A.; Ahmed, M.S.; Prodhan, M.D.H.; Akon, M.W. Determination of residue of diazinon and carbosulfan in brinjal and quinalphos in yard long bean under supervised field trial. Bangladesh J. Agric. Res. 2008, 33, 503-513. [CrossRef]

32. Jankowska, M.; Kaczynski, P.; Hrynko, I.; Lozowicka, B. Dissipation of six fungicides in greenhouse-grown tomatoes with processing and health risk. Environ. Sci. Pollut. Res. 2016, 23, 11885-11890. [CrossRef]

33. Panhwar, A.A.; Sheikh, S.A.S.; Soomro, A.H.; Abro, G.H. Residue removal of pesticides from brinjal using different processing methods. J. Basic Appl. Sci. 2014, 10, 431-438. [CrossRef]

34. Alen, Y.; Adriyani, F.; Suharti, N.; Nakajima, S.; Djamaan, A. Determination of profenofos pesticide residue in tomato (Solanum lycopersicum L.) using gas chromatography technique. Der. Pharm. Lett. 2016, 8, 137-141.

35. Prodhan, M.D.H.; Papadakis, E.N.; Papadopoulou-Mourkidou, E. Variability of pesticide residues in eggplant units collected from a field trial and marketplaces in Greece. J. Sci. Food Agric. 2018, 98, 2277-2284. [CrossRef] [PubMed]

36. Prodhan, M.D.H.; Akon, M.W.; Alam, S.N. Decontamination of organophosphorus insecticide residues from eggplant and yard long bean. Int. J. Expt. Agric. 2018, 8, 6-9. 